\title{
Stress and its Impacts among Pastors in the Moravian Church of Tanzania
}

\author{
Madaraka Angetile \\ University of Iringa, Tanzania \\ Corresponding Mail: madaraka.bukuku@gmail.com
}

\begin{abstract}
This study sought to establish stress and its potential impacts among pastors in the Moravian Church of Tanzania. The study adopted the mixed methods research approach whereby interview schedule and closed-ended questionnaire gathered data from respondents. The study comprised of 41 out of 120 population of pastors selected through simple random sampling, including one Bishop, four provincial and district leaders and thirty-six church pastors. Disagreement between church members and pastors was found to be one of stressors to pastors. It is therefore high time to intervene with strong means and alternatives so that pastors work in supportive environments. In order to enhance working morale among pastors it is essential to keep them motivated. Furthermore, the Moravian Church of Tanzania needs to review policies on working conditions so that pastors will work comfortably. The church should also establish regular seminars and trainings to educate pastors on essential skills, such as leadership and financial management in order to reduce unnecessary conflicts with church members and leadership as the conflicts are the causatives of stress.
\end{abstract}

Keywords: Impact, Moravian church, pastors, conflict, transfer, stress

\section{Introduction}

While stress is a natural feeling of not being able to cope with specific demands and events (Feliman, 2020), there is adequate literature evidence showing that pastors, like other people, are not immune to this emotional state (Ganesan, 2008; Lockwood, 2020; Wallace Wallace, ProescholdBell...\& Toth, 2012). Pastors, like other human service professionals, are vulnerable to stress. According to Lockwood (2020), pastors not only have the call but they struggle with common human issues including stress. The author further argue that pastors in Baptist Church in Southern Florida, USA, were suffering from silent frustrations of their call, personal temptations, family pressures and career desires while struggling to hold it together. Similarly, Kayler (2011) in the Western Northern Carolina found that the Methodist pastors' stress was a debilitating problem that not only harms them, but their families and their churches suffered as well. Particularly, Kayler found that the most stressors to pastors included time demand, spiritual discipline and church health issues.

Likewise, Chan, (2019) dealt with pastors who experienced stress and burnout in China and found that family was a significant predictor of pastors' overall burnout and emotional exhaustion was a significant predictor of occurrence of adverse health symptoms. Wooncho and Kwon (2020) in Korea observed the results of the intermediary role between the assistant pastor's sense of calling, pastoral stress, self-esteem and job satisfaction; the sense of calling gives a significant influence on job satisfaction by the medium of pastoral stress and self-esteem, and it shows the indirect mediated effect.

Pastors in Africa are also experience stress. Different studies exist on the existence of stress to pastors in the continent. Ganesan, (2008) studied on the effect of burnout and stress in the lives of pastors in South Africa and found that pastors conduct their work under enormous pressure, as they carry burdens of trying to meet unrealistic expectations of their congregations and the community at large. Bonsu (2016) asserts that the Ghanaian Pentecostal pastors while serving their congregations, communities, and families, most of them end-up into work-related stress. Lusambili and Kirimi (2015) established that occupational stress is a major limitation to work performance among

42 East African Journal of Education and Social Sciences (EAJESS) 2(4)42-45 
church pastors of Friends Church in Kenya. This is attributed to the fact that pastors become overstretched and end up being stressed while serving the church. Pastors often face formidable challenges to deal with and overcome the pressures that characterise their life and work. As a result, personal stress may cause a crisis in the pastoral ministry. In Africa, a priest or minister can be compelled to offer services to members of the congregation in areas where they do not have adequate training (Wallace, Proeschold-Bell...\& Toth, 2012). For instance, when congregants experience traumatic events and crises, they turn from priest or ministers to mental health professionals.

In Tanzania, pastors are susceptible to stress because they struggle to balance the frequently conflicting expectations of their congregations, denominational demands and family issues while attempting to stay true to their religious calling. This contention is supported by scholars (such as Lugoe, 1989; Santrock, 2016) who argue that individuals' (pastors inclusive) behaviors are heavily influenced by three reference systems: personal convictions; the professional reference system represented by denominational leadership and fellow pastors. Thus, most of impact of stress is mainly associated with those reference systems.

While stress to pastors is a global phenomenon due to unlimited number of factors, it is difficult for pastors, like any other professionals to cope up with the pressures of work. While this experience may affect the performance of their daily duties, this study sought to establish the impact of pastors' uncured stress in their services in the Moravian Church in Tanzania, Southern Province.

\section{Literature Review}

Stress among pastors is a growing problem around the World that affects not only their health and well-being, but also their productivity in the Church. Bonsu, (2016) argued that some of the impacts include lack of performance at work, decrease of productivity (especially in economic terms) and confusion among Christians. All these affect work and family relations of many pastors. Ortqvist and Wincent (2008) found that extreme cases of stress or traumatic events at work may lead to psychological problems and psychiatric disorders which may result in absence from work. Furthermore, people who experience stress may engage in unhealthy practices such as smoking and drinking (Cooper, 2004). They may also become distressed, irritable and may fail to enjoy their work and have difficult thinking and decision making.

According to Cox, Griffiths and Cox (1996), stress may contribute to some forms of physical illness. It also causes the body to respond innately by initiating a complex sequence of events. The fight or flight response may cause the body's metabolism to increase in preparation for expending energy on physical action, thereby curtailing unessential activities such as digestion, saliva and mucous production which can be harmful.

Stress can have short and long term consequences to pastors. These include deteriorating of the health (being prone to sickness) (Ganesan, 2008 \& Bonsu, 2016), lack of self-care; abnormal or bad behavior may appear to the pastor such as being cruel; daily massages or sermons to Christians can change and becomes less meaningful and there can be changes in behavior. Furthermore, stress can ignite frustration and anxiety as well as physiological and psychological relational problems in individuals, families and communities (Hill, Darling \& Raimond, 2003). Blaug, Kenyon and Lekhi (2007) added that stress may lead to headache, muscular tension, chest pains, indigestion, palpitations, disturbed sleep and increased susceptibility to respiratory infections. All these are harmful to the ministry and life of the pastor.

\section{Research Methodology}

The study employed the mixed research approach which was useful in order to produce complete knowledge necessary to the problem under investigation. The study comprised of 41 out of 120 population of pastors selected through simple random sampling, including one Bishop, four provincial and district leaders and thirty-six church pastors through the simple random sampling where names were written on pieces of papers and shuffled in a small container. Thereafter, the required pieces were randomly picked as participants through semi-structured interviews and questionnaire. The instruments were pre-tested to ensure validity and reliability. The pre-testing assisted to identify parts of instruments that were difficult for respondents to grasp. The researcher adhered to all ethical considerations such as voluntary participation, anonymity and protection of respondents from possible harms. Finally, the researcher obtained the research permit from responsible authorities prior to data collection. 


\section{Results and Discussion}

This section presents findings of the study under two research questions that were used to guide the analysis:

Research Question 1: What are the factors that contribute to stressful moments among pastors of the Moravian Church of Tanzania?

This research question was answered by data from the interview schedulule. Through interview, it was revealed that there are issues that church members come into disagreement with pastors and this caused the stressful experiences to pastors under investigation. One of the respondents, for instance, revealed that: "I remember the construction committee members held a different perspective from that of the pastor on the tender for a contractor, and this caused the pastor to experience some sort of stress."

One more respondent added that "whenever committee members in the congregations are not in favor of pastor's thoughts and approaches, they immediately report to church leaders." Another pastor added the following which indicates that pastors experienced stressful moments due to transfer from one station to another:

I thank God I have managed to build a house near the previous station. All that I needed was to acquire enough space so that I could work comfortably, but when I was informed about transfer, I was not sure of accommodation and working place. What I got in the new place of work was that the congregation did not own a house to accommodate pastors, so they rented a house in the community. Till now I have failed to cope up with the living environment.

Respondents revealed that as they are required to communicate with church leaders often, it becomes challenging when the pastors and church leaders do not relate well. One pastor, for instance, presented his painful experience and difficulties that he faced as follows:

In my life as pastor, I have faced difficulties in relating with top officials of the Province. This was mainly caused by some negative attitudes towards me that I have been engaged with family income generating projects. In fact, my family does not depend much on the salary, rather I managed to feed them and pay school fees from such projects as farming, livestock keeping and selling snacks which are prepared by my wife.

These findings are supported by a previous studies, for instance by Leads (2014) established that sources of work-related stress include conflict with co-workers or bosses, constant change of working places and changes to duties. The findings are also supported by Lockwood (2020) who also conducted a similar study in the USA and established that apart from preaching, the working load in the pastoral ministry can be overwhelming. The pastors were overwhelmed due to poor working conditions and inability to handle conflicting views. Therefore, it can commonly be agreed that internal conflicts and poor working conditions and relations are the causatives for stress to pastors.

Table 1: Perceived Impact of Pastors' Stress on Their Services

\begin{tabular}{llcccc}
\hline SN & Perceived Impact of uncured stress & SA & A & D & SD \\
\hline 1 & Dislike the job due to low salaries & $6(16.7)$ & $16(44.4)$ & $11(30.6)$ & $3(8.3)$ \\
2 & Being less effective due to unfavorable working conditions & $30(83.3)$ & $6(16.7)$ & 0 & 0 \\
3 & Unsettled misunderstanding among Christians & $31(86.1)$ & $5(13.9)$ & 0 & 0 \\
4 & Misunderstanding with Provincial leaders & $23(63.9)$ & $13(36.1)$ & 0 & 0 \\
5 & Failure to cope with transfers & $13(36.1)$ & $17(47.2)$ & $1(2.8)$ & 0 \\
6 & Becoming less interested with the work as a pastor & $19(52.8)$ & $13(36.1)$ & $4(11.1)$ & 0 \\
7 & Failure or misuse of finance of the church & $5(13.9)$ & $22(61.1)$ & $6(16.7)$ & $3(8.3)$ \\
\hline
\end{tabular}

Research Question 2: What are perceived impacts of stress on the ministry of pastors of the Moravian Church of Tanzania?

As seen in table 1 , respondents were given a questionnaire to indicate their agreement or disagreement with six potential impacts of uncured stress in the ministry. Analysis was done through determination of frequencies and percentages of responses based on five options as follows: $S A=$ strongly agree, $A=$ agree, $D=$ disagree and $S D=$ strongly disagree. 
Table 1 indicates that respondents either agreed or strongly agreed with all seven potential impacts. This means that disliking the job due to low salary, being less effective due to unfavorable working conditions, unsettled misunderstanding among Christians, misunderstanding with provincial leaders, failure to cope up with transfers and becoming less interested with the work as pastors as well as misuse of finances of the church are impacts they experienced in their life and ministry. These findings tally with those by Lusambili and Kirimi (2015) who found that majority of participants reported insecurity, difficulties due to low pay and financial difficulties as potential impact of stress. Findings also recorded negative impact commitments of pastors due to stress.

\section{Conclusions and Recommendations}

Based on the findings of the study, it is concluded that pastors suffered from stress. As it was revealed that one of the common factor responsible for stresses among pastors was disagreement between church members and pastors, it high time to intervene with strong means and alternatives so that pastors work in supportive environment. In order to enhance working morale among pastors it is essential to keep pastors motivated. The researcher recommended that the Moravian Church of Tanzania needs to review policies on working conditions so that pastors work comfortably. The church should also establish regular seminars and trainings to educate pastors on essential skills, such as leadership and financial management in order to reduce unnecessary conflicts with church members and leadership as the conflicts are the causatives of stress.

\section{References}

Blaug, R., Kenyon, A. \& Lekhi, R. (2007). Stress at work: A report prepared for The Work Foundation's Principal Partners. ttp://tiny url.com/kqcp867.

Bonsu, S. B. (2016). Lived Experiences Of Pentecostal Clergy In Ghana: Perceptions of Work-Life Balance on Families And Communities. PhD Thesis. Texas Woman University.

Chan, K. (2019). Experience of Stress and Burnout among Pastors in China. Journal of Pastoral care and Counselling 73 (4).
Cooper, C. (2004) Handbook of Stress Medicine and Health. ( $2^{\text {nd }}$ ed.). CRC Press, Florida.

Cox, T., Griffiths. A., \& Cox, S. (1996). Work-related stress in nursing: Controlling the risk to health. http://tinyurl.com/lqhdxxr.

Ganesan, C. (2008). An overview of the effects of Burnout and Stress in the lives of Ministers. University of KwaZulu Natal.

Hill,E,W,Darling, C.A, \& Raimond, N. M.(2003). Understanding boundary related stress in clergy families, Marriage and Family Review 35(1-2), 147-166.

Kayler,C (2011). Clergy stress A study of stressor and stress relieving among united Methodist Clergy Across Three Districts of the Western Northern Carolina Conference. PHD Thesis, Mzumbe University.

Leads, D. (2014). Workplace Anxiety, How to Deal with Stress, Conflict, Toxic Co-workers and Bosses, and Fear of Losing Your Job, United States of America: Inter - Varsity Press.

Lockwood, R. (2020). 10 Essential Tools for Overcoming Pastoral Stress; United States of America: Independent Publishers.

Lugoe, W. L. (1989). The Provision of Educational Guidance and Counselling Services in Diploma Teachers College in Tanzania. Unpublished M.A. Dissertation, University of Dar es Salaam.

Ortqvist, D. \& Wincent, J. (2008). Prominent consequences of role stress: a met analytic review. International Journal of Stress Management, 13(4), 399-422.

Santrock, J. W. (2016). A topical approach to lifespan development (Edisikedelapan). New York: McGraUw-Hill.

Wallace, A. C., Proeschold-Bell, R. J., LeGrand, S., James, J., Swift, R., Toole, D., \&Toth, M. (2012). Health programming for clergy: An overview of Protestant programs in the United States. Pastoral Psychology, 61(1), 113-143. 